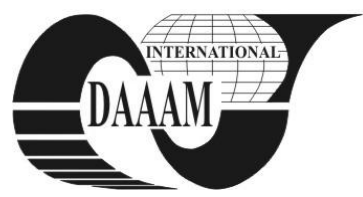

Annals of DAAAM for 2011 \& Proceedings of the 22nd International DAAAM Symposium, Volume 22, No. 1, ISSN 1726-9679 ISBN 978-3-901509-83-4, Editor B. Katalinic, Published by DAAAM International, Vienna, Austria, EU, 2011 Make Harmony between Technology and Nature, and Your Mind will Fly Free as a Bird Annals \& Proceedings of DAAAM International 2011

\title{
ADVANCED ELECTRIC RESISTANCE MACHINING TOOL
}

\author{
HRELJA, M[arko]; BREZOVNIK, S[imon]; BALIC, J[oze] \& BREZOCNIK, M[iran]
}

\begin{abstract}
Prototype manufacturing is getting nowadays more and more important. Obviously it is of the essence, that we try to convert CAD 3D-model to the prototype object as fast as possible, since the production could be started sooner, if the prototype gets approved. The aim of this research is aimed to design specific non-edged cutting too for expanded polystyrene, which would use rather electric current, converted to heat, using electrical resistance, so that prototype materials could get easily and efficiently machined. Several rules and constraints are avoided using this type of machining, so the selection of proper tool is reduced to selection of electrical current volume, to achieve proper material removal. It is proven, that with these kind of tool and material of the stock, we can achieve much smoother and accurate finish, than with classical machining tool, with the improvement of over 50\%, it depends if the melting parameter are selected carefully, within material limits, which is important, since expanded polystyrenes are highly heat-sensitive
\end{abstract}

Key words: machining, resistance cutting, electric resistance, CNC, robot machining

\section{INTRODUCTION}

Presently, we are facing great changes in manufacturing, and in production technologies, therefore, adjustments have to be made. Since mass production got dominant in second half of the $20^{\text {th }}$ century, industry and market demands production increasing. We can achieve this also with faster prototype design and build, so even prototypes can thoroughly get tested for the full loads, aerodynamics in wind tunnels, etc. In many cases, materials that are used for prototypes, are easily machined, though usually they have at least one poor quality. Conventional CNC machines, and even current robot machining systems are using standard cutting tools. If we want to avoid imperfections in prototype surface, we have to design proper tool, which helps us to create a model with a perfect surface for future testing of product.

In the fig. 1, we see the conventional cutting system, which works fine as long as we have stocks from standard materials. The cutting tool angles cause cutting forces, which affect stock, and cause material removing. Most of the materials, which are used for prototypes are rather foamy composition like expanded polystyrene, or tightly packed filler, bonded with polyurethane or any epoxy resins like cibatool/sikablock. If the cutting parameters and materials are not selected carefully, it may cause significant damage to either product or tool. In case of softer materials like expanded polystyrenes, only machined material gets affected.

For this reason, we assigned a research, to design a proper tool, that would allow identical machining processes, with same parameters as for the harder materials, so the manufacturing process won't be affected with loosing valuable time.

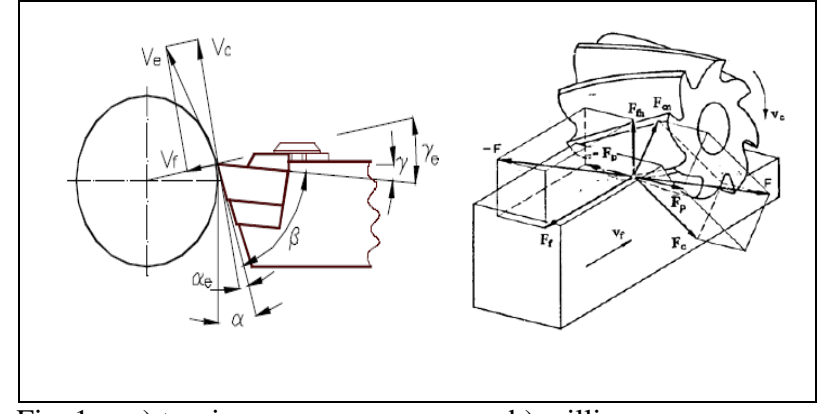

Fig. 1. a) turning

b) milling

\section{BACKGROUND}

Articles and literature that affect this paper are mainly based on standard cutting procedures, so as the advanced Hotedged tools, since the material to be removed is foam structured. First research and literature to be taken into account is the procedures of cutting (Franc Cus, 2009). Author describes cutting forces, material affections and general behavior of the procedures. This is followed by standard cutting procedures, with the target material (expanded polystyrene) study describes orthogonal cutting experiments performed on rigid foams including force measurements, tools with different rake angles, different cut increments, with results that surface is mainly dependant on cell size and cutting depth (Malak \& Anderson, 2005). A study on the influence of the sloped cutting angle on kerf width and part quality in the hot wire cutting of EPS foam for the VLM-s rapid prototyping processis also rewieved, system is based on 4-axis cutting machine, based on straight wire (Ahnetal, 2003). Same authors made another research about investigation of thermal characteristics of linear hot wire cutting system for variable lamination manufacturing (VLM) process by using expandable polystyrene foam. This is again based on the same principles and machines (Ahnetal, 2003). A flexible automated cutting system has been developed by (Jouanehetal, 1994), method is again based on straigth wire, clamped into system with tool turret, enabling 3-Dimensional cutting. A study on thermal characteristics of non-contact hottool for rapid feature detailing (RFD) process has also been made by (Kim et al., 2004).

\section{PROPOSED CONCEPT}

Technical solutions are mainly proposed as to inovationally improve the cutting processes for foam based materials from standard edge cutting tools, or tools based on straigth hot wire, to advanced tool, which mainly enables use of highly accurate robot machining processes in multi-axis cutting systems.

For now, results are based on numerical values for straight wire values, theoretical tool shapes and strategies to design the tool properly. Final tests and results will be achieved upon finishing the tool. 


\section{TOOL DESIGN}

Tool prototypes have been designed using 3-D CAD software, also analyzing of materials has been incorporated, to choose the proper wire as cutting element. Physical equations from electrics have also been applied in order to determine right current inputs, in order to melt material properly, while not affecting the accuracy.

Tool design paralleles have been taken from standard drilling, milling tools and hot edge wire cutters. Basic idea is, how to successfully merge the two components, to get proper tool, which minimizes material shredding, unwanted melting, etc. Expanded polystyrenes are known for its granulativity which causes with cutting edges collapse of material edges, where tool breaks out neighboring granules, when cutter touches with its tip the material or in the other extreme melts the material too far, if the tool diameter sits into cavity, where angular speeds cause the material to overheat, these anomalies turn up if we use standard high-speed cutters.

For elementary testing the tool has been designed as similar to milling tool as possible, in order to compare results. This calls for cylinder shape, which gets merged with the very same wire, which is used for straight cutting tools. The wire tends to expand, however the tool is designed that it compensates itself for this anomaly. The cutting wire must not be made from steel, hence these types of wires tend to expand even more, and at the same time it oxidises, which means basically burning, so steel wires tend to burn out too soon, or if too thin, they evaporate with time. Proper use is any resistance type wire, the thinner the better, optimal within $0.5 \mathrm{~mm}$ in diameter. If we choose to create different diameter tools, usage of longer resistance wire is required, which means higher resistance, and to overcome that obstacle, proper charger with variable input must be used. The input is also directly linked to material density.

Main components of the tool are tool core, electrical resistance wire, system which allowes to retain wire after it slightly expands, electrical charger with current regulator, which is needed in order to determine volume of current, flowing into tool, converting it to heat to cut the material.

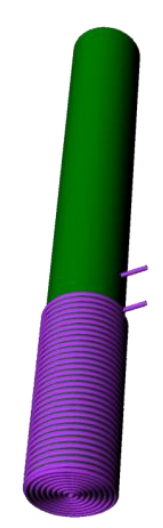

Fig. 2. First prototype of advanced heat material removal tool

The shape of the tool, the nature of cutting material and basics of electronic laws, determine that this type of tool does not need any rotation, despite the fact that it is based on milling tool. Material removal is executed through electric current, which gets converted through resistance wire into heat, and generated heat is melting the material, leaving no traces behind, since the material gets fully evaporated. This removes additional feature in standard cutting procedures, the cut off transporting system, which is essential to maintain efficient production.

\section{MACHINE CONFIGURATION}

Tool has been designed with standard material removal machines in mind, since these will not change in near future, so essential shape of milling tool has been retained. Also, no special knowledge for the machine operator is required, subsequently no additional education is necessary, since all tools could be provided with charts with proper setup parameters according to the stock material. The only additional knowledge that worker should have, would be the resistance capabilities of resistance wire, in order not to heat it too much, since the wire itself may snap if underheated, or melt if overheated. Tool has been designed mainly for robotic machining purposes, although it is usable in standard CNC machines too, however, for the successful material removal, it is essential to make adjustments to machine in terms of proper electronics usage for resistance tool heating, etc.

\section{CONCLUSION}

For rapid prototyping, easily workable materials are essential. For large scale prototypes, exhibition props, even for factory test in smaller scales (e.a. wind tunnel testing), we need a proper model of our product, either in small scale or in final scale. For this purposes we have chosen easily workable expanded polystyrenes in different denstities, which could be cut with hot edged tools. For achieving complex shapes, the standard use of hot wire simply isn't enough, so it is essential to develop a tool, which could perform as a standard cutter, with hot wire abilities. The first impressions of our product seems to be in right direction, with next step to eliminate the wire and substitute it with the smooth edged material to avoid wire markings in the product, that makes the surface uneven (e.a. wavy). The next step in tool evolution is also designing a prototype for turning technology, including its periphery, for successful turning procedures, such as fixed turntable, which will be placed into optimal robotic toolpath to achieve maximum capabilities in terms of efficiency. Athough we base the tools for mostly robotic use, the shape is designed also for conventional CNC machines in mined, so wide usage is possible.

\section{REFERENCES}

Cus F. (2004). High speed cutting ands pecial material remova ltechnologies, Faculty of mechanical engineering Maribor, ISBN: 86-435-0639-7, Maribor

Ahn D.G., Lee S.H. \& Yang D.Y.. (2003). A study on the influence of the sloped cutting angle on kerf width and part quality in the hot wire cutting of EPS foam for the VLM-s rapid prototyping process. Available from: http://sciencedirect.com Accessed: 2010.11.05

Ahn D.G., Lee S.H. \& Yang D.Y.. (2003).Investigation into thermal characteristics of linear hot wire cutting system for variable lamination manufacturing (VLM) process by using expandable mpolystyrene foam. Available from: http://sciencedirect.com Accessed: 2010.11.05

Grote K. H. \&Antonsson E. K. (2009).Springer handbook of mechanical engineering.Springer.ISBN 978-3-540-491316, United states of America

Kim H.C., Ahn D.G., Lee S.H. \& Yang D.Y.. (2004). A study on thermal characteristics of non-contact hot-tool for rapid feature detailing (RFD) process. Available from: http://sciencedirect.com Accessed: 2010.11.05

Lokensgard E., Richardson L. T. (2004). Industrial plastics: theory and applications, $4^{\text {th }}$ edition. Thomson / Delmar learning, ISBN: 1-4018-0469-1, United states of America

Jouaneh M., Hammad A. \& Datseris P. (1996). A flexible automated foam cutting system. Available from: http://sciencedirect.com Accessed: 2011.1.15 